\title{
Comparative evaluation of postpartum versus post MTP insertion of intrauterine contraceptive device
}

\author{
Isha Gutgutia, Kumari Usha Rani*, Shashi Prateek, Renu Arora, Shubham
}

Department of Obstetrics \& Gynecology, VMMC \& Safdarjang Hospital, New Delhi, India

Received: 26 October 2014

Accepted: 10 November 2014

*Correspondence:

Dr. Kumari Usha Rani,

E-mail: usharani10066@yahoo.com

Copyright: (C) the author(s), publisher and licensee Medip Academy. This is an open-access article distributed under the terms of the Creative Commons Attribution Non-Commercial License, which permits unrestricted non-commercial use, distribution, and reproduction in any medium, provided the original work is properly cited.

\begin{abstract}
Background: This study was planned to evaluate acceptability, safety and continuation rate of postpartum intrauterine contraceptive device (PPIUCD) and to compare it with well accepted post MTP IUCD in Indian population.

Methods: This was a prospective study conducted in VMMC and Safdarjang Hospital, New Delhi, India. Copper T 380-A was inserted in 100 woman in postpartum period and in 100 woman in post MTP period. Follow up done at 6 weeks, 3 months and 6 months. Safety was assessed in terms of expulsion, IUCD failure/pregnancy rate, perforation, removal of IUCD, visibility of strings and various complain at each visit. Continuation rate along with their level of satisfaction was compared at the end of 6 months. SPSS software, Chi-square test and student $\mathrm{T}$ test were used for analyzing the results. $P$ value $\leq 0.05$ considered as significant.

Results: Acceptance of post MTP IUCD was more than PPIUCD. There was statistically no significant difference in expulsion rate, removal of IUCD and various complaints. There was no case of perforation in either group. Non visibility of strings was major cause of concern and apprehension in PPIUCD group. Only one case of pregnancy was reported in PPIUCD group while no failure was reported in post MTP group. Continuation rate and level of satisfaction were comparable in both groups.
\end{abstract}

Conclusions: PPIUCD is equally safe and effective as post MTP IUCD.

Keywords: Cu T-380 A, Safety, Acceptability, Continuation, Expulsion

\section{INTRODUCTION}

The contraceptive prevalence rate in India is $56.3 \%$ and unmet need is $12.8 \%$ according to National Family Health Survey-3, 2005-06. Unmet need of contraception in first year postpartum among Indian women is even higher; it is $65 \%$ according to United States Agency for International Development 2009. The reasons for this are many, including lack of awareness, non-availability of accessible family planning services and restricted women's mobility due to mostly cultural factors. Hence getting an institutional delivery or a Medical Termination of Pregnancy (MTP) is the only times when they get an opportunity to visit a health set up. Postpartum period is an ideal time to begin contraception, as women are highly motivated to adopt contraception at this time. Advantages of postpartum insertion include convenience to the patient and service provider, the ease of insertion, and the cost savings associated with providing family planning at birth rather than at a subsequent visit. However few side effects like bleeding, abdominal pain, perforation and expulsion are also reported. Major concern being higher risk of expulsion which is about $8-15 \%{ }^{1-3}$ in postpartum cases.

In India although PPIUCD insertion is approved by Government of India But it has not gained much popularity - majorly due to lack of complete and correct information both among the providers \& acceptors. In our country various family planning programmes have made 
post MTP IUCD insertion practical and acceptable to large extent but post-partum IUCD has miles to reach.

The present study has been undertaken to evaluate the acceptability, safety and continuation rate of PPIUCD in Indian population and to compare it with post MTP IUCD. We have done this study as in both cases IUCD is inserted immediate post pregnancy. As Post MTP IUCD is well accepted method in India, comparative result will help in acceptance and decision making to both providers $\&$ acceptors regarding PPIUCD which is still in infancy in India.

Immediate postpartum intrauterine contraceptive device is WHO MEC criteria 1 and it includes:

1. Post placental: Insertion within 10 minutes after expulsion of the placenta following a vaginal delivery.

2. Insertion within 48 hours of delivery.

3. Intracaesarean: Insertion during a caesarean section, after removal of placenta.

\section{METHODS}

This was a Prospective cohort study conducted in the department of obstetrics and gynecology, Vardhman Mahavir medical college \& Safdarjang hospital, New Delhi, India from September 2011 to August 2012. This study was approved by institute ethics committee.

\section{Sample size}

Study was divided into two groups. 100 women recruited in each group.

Group A - Postpartum IUCD, it includes post placental, within 48 hours of delivery and intracaesarean.

Group B - Post MTP IUCD, MTP done by suction evacuation method in first trimester was enrolled for the study.

$\mathrm{Cu}$ T 380 A was used as intrauterine contraceptive device.

\section{Inclusion criteria}

- Immediate postpartum period (within 48 hours)

- First trimester MTP by suction \& evacuation method

- Women willing to return for follow up visits

- Women having no contraindication of IUCD insertion (WHO MEC category 1 or 2)
- Women having previous menstrual cycles regular for at least 6 months before the current pregnancy

\section{Exclusion criteria}

- $\quad$ Prolonged rupture of membranes ( $>18$ hours)

- Fever or any other signs of pelvic infection

- Postpartum hemorrhage

- Puerperal sepsis

- Distorted uterine cavity by fibroid uterus

- Severe anemia $(<7 \mathrm{gm} \%)$

- Any bleeding disorder

- Extensive genital trauma during delivery

- Women in WHO MEC category 3 or 4

\section{Insertion technique}

Post-placental and insertion within 48 hours of delivery was done by Kelly's forceps.

Intracaesarean insertion by hand through uterine incision.

Post MTP insertion by withdrawal method.

\section{Follow up visits}

There were three follow up visits.

- $1^{\text {st }}$ visit was at 6 weeks in group A and after first menses or 6 weeks whichever is earlier in group B

- $\quad 2^{\text {nd }}$ visit was at 3 months

- $3^{\text {rd }}$ visit was at 6 months

\section{Primary outcome measures}

- Acceptability rate

- Visibility of strings and expulsion

- Incidence and spectrum of complications

- Perforation

- IUCD failure/pregnancy rate

- IUCD removal rate

- Continuation rate 


\section{Secondary outcome measures}

- Perception of pain during IUCD insertion

- Patients level of satisfaction with treatment

- Recommendation of IUCD to others

\section{Statistical analysis}

The statistical significance of categorical variables was determined by Chi-square test and quantitative variables were determined by student $\mathrm{T}$ test.

The $\mathrm{P}$ value $\leq 0.05$ was taken as level of statistical significance. Data was analyzed using SPSS statistical software version 17.0.

\section{RESULTS}

The socio-demographic profile in both groups was comparable except for literacy rate. Education renders people more receptive to new ideas and practices.

Low educational status in group $\mathrm{A}$ in comparison to group B may be one of the reasons behind low acceptability of PPIUCD in comparison to post MTP IUCD in addition to the fact that it is a new method.

Table 1: Demographic profile.

\begin{tabular}{|c|c|c|c|}
\hline & Group A & Group B & $\begin{array}{l}P \\
\text { value }\end{array}$ \\
\hline $\begin{array}{l}\text { Total woman } \\
\text { counseled }\end{array}$ & 379 & 186 & \\
\hline Acceptors & $100(26.39 \%)$ & $100(53.76 \%)$ & \\
\hline $\begin{array}{l}\text { Mean age } \pm \text { SD } \\
\text { (years) }\end{array}$ & $27.58 \pm 2.92$ & $26.74 \pm 3.02$ & 0.307 \\
\hline \multicolumn{4}{|l|}{ Education wife } \\
\hline Illiterate & 29 & 15 & \multirow{2}{*}{$<0.05$} \\
\hline $10^{\text {th }}$ or above & 22 & 43 & \\
\hline \multicolumn{4}{|c|}{ Education husband } \\
\hline Illiterate & 21 & 14 & \multirow{2}{*}{$<0.05$} \\
\hline $10^{\text {th }}$ or above & 45 & 65 & \\
\hline \multicolumn{4}{|c|}{ Socioeconomic status } \\
\hline Lower & $53(53 \%)$ & $49(49 \%)$ & \multirow{2}{*}{0.921} \\
\hline Other & $47(47 \%)$ & $51(51 \%)$ & \\
\hline $\begin{array}{l}\text { No. of living issue } \\
(\text { mean } \pm \text { SD) }\end{array}$ & $2.53 \pm 0.89$ & $2.32 \pm 0.76$ & 0.23 \\
\hline $\begin{array}{l}\text { No. of previous } \\
\text { MTP }(\text { Mean } \pm \text { SE) }\end{array}$ & $0.96 \pm 0.084$ & $0.77 \pm 0.071$ & 0.167 \\
\hline \multicolumn{4}{|c|}{ Contraceptive awareness } \\
\hline Yes & $68 \%$ & $72 \%$ & \multirow{2}{*}{0.537} \\
\hline No & $32 \%$ & $28 \%$ & \\
\hline \multicolumn{4}{|c|}{ Previous use of any contraception } \\
\hline Yes & $33 \%$ & $43 \%$ & \multirow{2}{*}{0.145} \\
\hline No & $67 \%$ & $57 \%$ & \\
\hline
\end{tabular}

Table 2: Distribution of women with time of counseling and acceptance of IUCD.

\begin{tabular}{|llll|}
\multirow{2}{*}{ Group } & $\begin{array}{l}\text { Time of } \\
\text { counseling }\end{array}$ & $\begin{array}{l}\text { No. of } \\
\text { women } \\
\text { counseled }\end{array}$ & $\begin{array}{l}\text { No. of women } \\
\text { accepted }\end{array}$ \\
\hline \multirow{2}{*}{$\begin{array}{l}\text { Postpartum } \\
\text { IUCD group }\end{array}$} & Antenatal & 145 & $34(23.45 \%)$ \\
\cline { 2 - 4 } & Early labour & 166 & $55(33.13 \%)$ \\
\cline { 2 - 4 } & Postpartum & 68 & $11(16.18 \%)$ \\
\hline $\begin{array}{l}\text { Potal } \\
\text { IUTP }\end{array}$ & 379 & $100(26.39 \%)$ \\
\hline
\end{tabular}

Acceptance of post MTP IUCD was more than PPIUCD (53.76\% versus $26.39 \%)$.

Counseling done during early labour was most effective while it was least effective during postpartum period.

Table 3: Insertion related factors.

\section{Group A Group B P value}

Provider's perception on ease of insertion on a scale of 0 to10

\begin{tabular}{|lll}
\hline Very easy (1-3) & 83 & 90 \\
\cline { 1 - 2 } Easy (4-6) & 15 & 10 \\
\cline { 1 - 2 } Difficult (7-10) & 2 & 0 \\
\cline { 1 - 2 } \pm Mean \pm SD & $2.68 \pm 1.17$ & $2.54 \pm 0.881$
\end{tabular}

Acceptor's perception of pain during insertion on visual analogue scale of 0 to 10

\begin{tabular}{lll} 
Mild pain (0-3) & $49(55 \%)$ & $85(85 \%)$ \\
\hline Moderate (4-6) & $36(40.5 \%)$ & $15(15 \%)$
\end{tabular}

Moderate (4-6) $36(40.5 \%) \quad 15(15 \%)$

No statistically significant difference was noted in ease of insertion among both the groups.

Among the two difficult insertions in group A, both were insertions within 48 hours of delivery.

In present study IUCD insertion was $76 \%$ post placental, $13 \%$ within 48 hours of delivery and $11 \%$ intracaesarean.

Though perception of pain on visual analogue scale (Score of 0 represents no pain and 10 represents severe pain experienced ever) was found to be statistically significant $(\mathrm{P}<0.05)$.

But this was due to the fact that in post MTP insertion, women were under intravenous sedation so their pain perception was comparatively less than group A insertions.

All four patients complaining of severe pain in PPIUCD group were of within 48 hours of delivery insertion when the woman is actually more apprehensive and already have post-delivery episiotomy/perineal pain. 
Table 4: Visibility of IUCD strings and expulsion in follow up visits.

\begin{tabular}{|c|c|c|c|c|c|c|}
\hline \multirow{2}{*}{ Follow up visits } & \multicolumn{2}{|l|}{6 weeks } & \multicolumn{2}{|l|}{3 months } & \multicolumn{2}{|l|}{6 months } \\
\hline & Group A & Group B & Group A & Group B & Group A & Group B \\
\hline No. of women followed & 100 & 100 & 96 & 98 & 91 & 95 \\
\hline IUCD strings visible & $43(43 \%)$ & $99(99 \%)$ & $59(61.5 \%)$ & $96(97.9 \%)$ & $73(80.2 \%)$ & $94(98.9 \%)$ \\
\hline No. of missing strings & 57 & 1 & 37 & 2 & 18 & 1 \\
\hline IUCD visible on USG & 56 & 0 & 36 & 0 & 18 & 0 \\
\hline Complete expulsion & 1 & 1 & 1 & 2 & 0 & 1 \\
\hline Partial expulsion & 2 & 1 & 3 & 1 & 1 & 0 \\
\hline
\end{tabular}

Two women in group A were lost to follow-up after $1^{\text {st }}$ visit. Rest all women completed follow-up till terminal events (expulsion, removal, pregnancy) or up to 6 months of study period. Missing strings/nonvisibility of strings was one of the major causes of concern and apprehension in both acceptor and provider in PPIUCD insertion compared to post MTP IUCD insertion. IUCD strings were visible in $80.2 \%$ cases in group $\mathrm{A}$ at the end of 6 months.
Expulsion rate in group A was $8 \%$ (2\% complete and $6 \%$ partial expulsion) and in group $B$ it was $6 \%(4 \%$ complete and $2 \%$ partial).

Partial expulsion defined as an IUD protruding from the cervical OS. Maximum no of expulsions were detected within 3 months of insertion. The difference was statistically insignificant ( $\mathrm{P} \geq 0.05)$.

Table 5: Complaints during each follow up visit.

\begin{tabular}{|lllllll|}
\hline & 6 weeks & & 3 months & months & Group B \\
\hline Pain lower abdomen & Group A & Group B & Group A & Group B & Group A & Group \\
\hline Discharge/ itching p/v & 9 & 8 & 6 & 6 & 4 & 7 \\
\hline Bleeding/menorrhagia & 7 & 6 & 11 & 9 & 3 & 7 \\
\hline Persistent lochia/spotting on \& off & 6 & 5 & 10 & 14 & 7 & 7 \\
\hline Uncomfortable to husband & 2 & 3 & 2 & 1 & 1 & 0 \\
\hline Weakness & 5 & 6 & 1 & 6 & 1 & 7 \\
\hline Worried about thread & 5 & 0 & 5 & 0 & 5 & 0 \\
\hline P value & $>0.05$ & & $>0.05$ & & $>0.05$ & \\
\hline
\end{tabular}

Perforation: There was no case of perforation in either group. Pregnancy/IUCD failure: Only one case of pregnancy was detected with IUCD in situ in group A. No failure was reported in group B.

Table 6: Reasons of removal of IUCD in each group.

\begin{tabular}{|c|c|c|c|c|c|c|}
\hline \multirow{2}{*}{ Reasons of removal } & \multicolumn{2}{|l|}{6 weeks } & \multicolumn{2}{|l|}{3 months } & \multicolumn{2}{|l|}{6 months } \\
\hline & Group A & Group B & Group A & Group B & Group A & Group B \\
\hline Wanting pregnancy & 0 & 0 & 0 & 0 & 0 & 0 \\
\hline Pelvic infection & 0 & 0 & 0 & 0 & 0 & 0 \\
\hline Partial expulsion & 2 & 1 & 1 & 1 & 0 & 0 \\
\hline Bleeding related complaints/spotting & 0 & 2 & 2 & 1 & 2 & 1 \\
\hline IUCD failure/ Pregnancy & 0 & 1 & 0 & 0 & 0 & 0 \\
\hline Pain lower abdomen & 0 & 0 & 0 & 0 & 1 & 0 \\
\hline Uncomfortable to husband & 0 & 0 & 0 & 1 & 0 & 0 \\
\hline Total removal & 2 & 4 & 3 & 3 & 3 & 1 \\
\hline
\end{tabular}


At the end of 6 months IUCD removal rate was $9 \%$ in group $\mathrm{A}$ and $7 \%$ in group $\mathrm{B}$ for various reasons. The data showed no significant difference on applying Chi-square test, $\mathrm{P}>0.05$. Partially expelled IUCD which were removed and IUCD if not reinserted were included as one of the reasons for removal.

\section{Continuation, satisfaction and further recommendation of IUCD}

The continuation rate of IUCD at the end of 6 months was $85 \%$ in group A ( $8 \%$ expulsion, $5 \%$ removal for reason other than expulsion and $2 \%$ lost to follow-up after $1^{\text {st }}$ visit) and $88 \%$ in group $\mathrm{B}(6 \%$ expulsion and $6 \%$ removal for reason other than expulsion). The difference is not statistically significant. Satisfaction with IUCD use (on Likert's scale of satisfaction from 1-5) and recommendation of IUCD to other women was assessed at 6 months of follow up or at the time of discontinuation.

On statistical analysis the difference in level of satisfaction between two groups was not significant $(\mathrm{P}=$ $0.615)$.

Table 7: Level of satisfaction at end of 6 months.

\begin{tabular}{|lll|}
\hline Client satisfaction & Group A & Group B \\
\hline Very satisfied & 8 & 4 \\
\hline Satisfied & 55 & 60 \\
\hline Neutral & 23 & 25 \\
\hline Dissatisfied & 11 & 7 \\
\hline Very dissatisfied & 3 & 4 \\
\hline P value & P value $=0.615$ \\
\hline
\end{tabular}

$66 \%$ women in group A and $63 \%$ in group B were willing to recommend IUCD as a satisfactory method of contraception to others. $15 \%$ in both groups did not want to recommend while $19 \%$ in group A and $22 \%$ in group B were undecided about this though they themselves are continuing with the method.

There was no statistical difference between the two groups in this parameter $(\mathrm{P}=0.865)$.

\section{DISCUSSION}

Post MTP IUCD insertion is a well-accepted method for many years in several countries including India. Cochrane database of systematic reviews 2002 after analyzing several trials concluded that immediate insertion of an IUCD after abortion is both safe and practical. ${ }^{4}$ Use of $\mathrm{Cu} \mathrm{T} 380 \mathrm{~A}$ in immediate postpartum period is still not very popular in India. Few concerns like higher expulsion rate, perforation, non-visibility of strings have limited its use. Cochrane database 2010 concluded that PPIUCD appeared safe and effective, early follow-up may be important in identifying expulsion. ${ }^{5}$

\section{Acceptability}

In the present study acceptability of post MTP IUCD was $53.76 \%$. Study done by El-Tagy A et al. ${ }^{6}$ has shown acceptability of $42 \%$ in post abortal IUCD insertion.

In our study PPIUCD acceptability was $26.39 \%$. Another Indian Studies done by Katheit et al. ${ }^{3}$ and Gupta A et al. ${ }^{7}$ found acceptability rate $18.8 \%$ and $14.4 \%$ respectively. Acceptability is low probably because PPIUCD is a new concept in India. A study from Egypt, Safat et al. ${ }^{8}$ had shown 28.9\% acceptability. Counseling during early labor in our study had highest acceptance rate of $33.13 \%$. Jenabi E et al. $2006^{9}$ has also shown that women are more receptive to advice given antenatally.

Post MTP IUCD insertion was very easy (Mean \pm SD is $2.54 \pm 0.881)$ as over the years' experience and already dilated cervical OS makes the procedure simple. Similarly El-Tagy A et al. ${ }^{6}$ also reported no difficulty during insertion.

PPIUCD insertion was also perceived to be very easy in our study (Mean $\pm \mathrm{SD}$ is $2.68 \pm 1.17$ ). Majority of women in post placental insertion group express mild discomfort and took the procedure as a part of delivery procedure, whereas insertion within $48 \mathrm{hrs}$ of delivery was comparatively more painful. Dahlke et al. ${ }^{10}$ also reported similar findings.

The strings were not visible after PPIUCD insertion in any of the subjects due to large uterine size. Involution of uterus descends the thread downward and makes strings visible. Visibility increased in successive follow up visits. It was $80.2 \%$ at the end of 6 months. Similarly Lara RR et al, 2012 has reported high visibility of strings, it was $90.2 \%$ at the end of one year. ${ }^{11}$

\section{Uterine perforation}

No cases of perforation were reported during insertion or further follow up visits in both the groups. Ahmed et $\mathrm{al}^{6}$ and Drey EA et al. ${ }^{12}$ also reported no perforation and Cochrane database $2002^{4}$ reviewed perforation to be rare and uncommon following immediate post MTP insertion. Various researchers also reported negligible or no uterine perforation following immediate PPIUCD insertion. ${ }^{2,13-15}$ Celen et al. ${ }^{2}$ studied 235 cases and found no perforation while Cole et al. ${ }^{13}$ found one perforation out of 3800 cases. Therefore both post MTP IUCD and PPIUCD insertion has negligible and comparable perforation risk.

\section{IUD failure/pregnancy}

No failure was detected after post MTP insertion in present study. Similarly El-Tagy A et al. ${ }^{6}$ and Bednarek $\mathrm{PH}$ et al $2009^{16}$ reported no cases of failure. Das CR et al. ${ }^{17}$ studied 60 cases and reported one case $(1.6 \%)$ of failure after post MTP insertion. 
Occurrence of pregnancy with IUCD in situ was reported in one woman (1\%) at 3 months of follow up in PPIUCD group. Other studies. ${ }^{14-15}$ also reported similar rate of pregnancy with IUCD in situ, Xu et al. ${ }^{14}$ reported no pregnancy out of 910 cases while Brenar $\mathrm{PF}^{15}$ studied 100 cases and reported one pregnancy. These data shows that both Post MTP IUCD and PPIUCD insertion has low, uncommon and comparable failure rates.

\section{Expulsion}

Expulsion was the major concern in both groups. It was $6 \%$ in group B. Comparable expulsion rates, 5\% were reported by Bedranek PH et al. ${ }^{16}$ while Drey EA et al. ${ }^{12}$ reported only $0.8 \%$.

In group A expulsion rate was $8 \%$. Higher expulsion rate $14.3 \%$ has been recorded by Eroglu et al. ${ }^{1}$ and $12.3 \%$ by Celen at al. ${ }^{2}$ at the end of one year. Another Indian study by Katheit et al. ${ }^{3}$ recorded $10.5 \%$ expulsion rate at 6 weeks follow up. Low expulsion rate in our study may be because our hospital is identified as national training centre and our doctors are trained in inserting PPIUCD. Cole LP et al. ${ }^{13}$ had stated that training is essential to lower the expulsion rate.

Also $76 \%$ cases in this group in our study were post placental insertion which has lower expulsion rates than within 48 hours of delivery insertion as reported by Brenner PF et al. ${ }^{15}$ and Morrison $\mathrm{C}$ et al. ${ }^{18}$ We have also found that all women were breast feeding though not exclusive till 6 months. $\mathrm{Xu}$ JX et al. ${ }^{19}$ noted higher expulsion rates $22.4 \%$ in non-breast feeding women as compared to $11.9 \%$ in breast feeding women.

\section{IUCD removal}

It was $7 \%$ in group B, majorly (4 out of 7) because of bleeding related problems. Das CR et al. ${ }^{17}$ and Tagy A et al. $^{6}$ also reported respectively $8.3 \% \& 4.37 \%$ removal and mainly due to bleeding problems.

PPIUCD removal rate in our study was $9 \%$. Major cause for removal was bleeding related complaints and partial expulsion. Partially expelled IUCD which was removed and if not reinserted were included in removal in our study. Gupta A et al. ${ }^{7}$ reported 5.6\% PPIUCD removal at 6 months follow up, mainly because of social reason, bleeding and pain. Lara et al. ${ }^{11}$ reported $4.5 \%$ removals at 1 year follow-up.

\section{Continuation}

Continuation rate of post MTP IUCD at 6 months was $88 \%$. Bedranek PH $2009^{16}$ stated $92.3 \%$ continuation and Drey et al. ${ }^{12} 6.5 \%$ discontinuation rate making post MTP highly acceptable and effective method.

Continuation rate for PPIUCD insertion at 6 months was $85 \%$. Similarly Celen et al. ${ }^{2}$ has shown continuation rate of $87.6 \%$ and Dahlke et al. ${ }^{10} 87 \%$ at 6 months.

\section{Overall Satisfaction and recommendation to others}

At the end of 6 months $89 \%$ women were satisfied after post MTP and $86 \%$ after PPIUCD insertion. Drey EA $2009^{12}$ reported satisfaction level of $93.8 \%$ following immediate post abortal IUCD insertion. Satisfaction level between both the groups was comparable and around $65 \%$ in either group were willing to recommend this method to others in our study.

\section{CONCLUSION}

It is concluded from our study that PPIUCD insertion is equally safe and effective method of contraception as post MTP IUCD. Though slightly higher expulsion rate $12-15 \%$ was reported by various studies, this also means continuation rate of $85-88 \%$ which is acceptable considering high unmet need in our country and limited resources especially in rural areas. Proper training of the provider, good counseling and better media coverage will increase its acceptability and can make PPIUCD a milestone for the success of contraception programs in India.

\section{Funding: No funding sources}

Conflict of interest: None declared

Ethical approval: The study was approved by the institutional ethics committee

\section{REFERENCES}

1. Eroglu K, Akkuzu G, Vural G, Dilbaz B, Akin A, Taskin L, et al. Comparison of efficacy and complications of IUD insertion in immediate postplacental/early postpartum period with interval period: 1 year follow up. Contraception. 2006;74(5):376-81.

2. Celen S, Moroy P, Sucak A, Aktulay A, Danisman N. Clinical outcome of early post placental insertion of intrauterine contraceptive devices. Contraception. 2004;69(4):279-82.

3. Katheit G, Agarwal J. Evaluation of PPIUCD in terms of awareness, acceptance and expulsion in a tertiary care centre. Int J Reprod Contracept Obstet Gynecol. 2013;2:539-43.

4. Grimes D, Schulz K, Stanwood N. Immediate postabortal insertion of intrauterine devices. Cochrane Database Syst Rev. 2002;(3):CD001777.

5. Grimes DA, Lopez LM, Schulz KF, Van Vliet HA, Stanwood NL. Immediate post-partum insertion of intrauterine devices. Cochrane Database Syst Rev. 2010 May;(5):CD003036.

6. EL-Tagy A, Sakr E, Sokal DC, Issa AH. Safety and acceptability of post-abortal IUD insertion and the importance of counseling. Contraception. 2003;67(3):229-34.

7. Gupta A, Verma A, Chauhan J. Evaluation of PPIUCD versus interval IUCD (380 A) insertion in a teaching hospital. Int $\mathrm{J}$ Reprod Contracept Obstet Gynecol. 2013;2:204-8. 
8. Safwat A. Mohamed, Momen A. Kamel, Omar M. Shaaban, Hossam T. Salem. Acceptability for the use of postpartum intrauterine contraceptive devices: Assiut experience. Med Principal Pract. 2003;12(3):170-5.

9. Jenabi E, Alizade SM, Baga RI. Continuation rates and reasons for discontinuing TCu380A IUD use in Tabriz, Iran. Contraception. 2006;(7496):483-6.

10. Dahlke JD, Terpstra ER, Ramseyer AM, Busch JM, Rieg T, Magann EF. Postpartum insertion of levonorgestrel: intrauterine system at three time periods: a prospective randomized pilot study. Contraception. 2011 Sep;84(3):244-8.

11. Lara Ricalde R, Velázquez Ramírez N, Reyes Muñoz E, Baca Olivo Pdel R. Posplacenta intrauterine device. Guide wires not visible. Gynecol Obstet Mex. 2012 Mar;80(3):201-7.

12. Drey EA, Reeves MF, Ogawa DD, Sokoloff A, Darney PD, Steinauer JE. Insertion of intrauterine contraceptives immediately following first-and second-trimester abortions. Contraception. 2009;79(5):397-402

13. Cole LP, Edelman DA, Potts DM, Wheeler RG, Laufe LE. Postpartum insertion of modified intrauterine devices. J Reprod Med. 1984;29(9):67782.

14. Xu JX, Rivera R, Dunson TR, Zhuang LQ, Yang XL, Ma GT, et al. A comparative study of two techniques used in immediate post placental insertion (IPPI) of the copper T-380A IUD in Shanghai,
People's Republic of China. Contraception. 1996 Jul;54(1):33-8.

15. Brenner PF. A clinical trial of the delta-T intrauterine device: immediate postpartum insertion. Contraception. 1983 Aug;28(2):135-47.

16. Bednarek PA, Creinin MD, Reeves MF, Cwiak CA, Espey E, Jensen JT. Immediate intrauterine device insertion following suction aspiration between 5-12 weeks of gestation increases rates of insertion and utilization compared to scheduled delayed insertion. Contraception. 2009;80(2):203.

17. Das CR, Pradhan G. Study of side effects of $\mathrm{Cu}-\mathrm{T}$ as intra-uterine contraceptive device in post medical termination of pregnancy and interval Cases. J Indian Med Assoc. 1995 Oct;93(10):375-6.

18. Morrison C, Waszak C, Katz K, Diabate F, Mate EM. Clinical outcomes of two early postpartum IUD insertion programs in Africa. Contraception. 1996 Jan;53(1):17-21.

19. $\mathrm{Xu}$ JX, Reusche C, Burdan A. Immediate post placental insertion of the intrauterine device: a review of Chinese and the world's experiences. Adv Contracept. 1994;10(1):71-82.

DOI: $10.5455 / 2320-1770$. ijrcog20150204

Cite this article as: Gutgutia I, Rani KU, Prateek S, Arora R, Shubham. Comparative evaluation of postpartum versus post MTP insertion of intrauterine contraceptive device. Int J Reprod Contracept Obstet Gynecol 2015;4:23-9. 